\title{
Disentangling the relative influence of regeneration processes on marsh plant assembly with a stage-structured plant assembly model
}

\author{
Man $\mathrm{Qi}^{\mathrm{a}}{ }^{\mathrm{b}}$, Feng Zhao ${ }^{\mathrm{a}}$, Tao Sun ${ }^{\mathrm{b}, *}$, Alexey Voinov ${ }^{\mathrm{c}}$ \\ ${ }^{a}$ Key laboratory of Geographical Process Analysis \& Simulation of Hubei Province/College of Urban and Environmental Sciences, Central China Normal University, \\ Wuhan 430079, China \\ ${ }^{\mathrm{b}}$ State Key Laboratory of Water Environment Simulation, School of Environment, Beijing Normal University, Beijing 100875, China \\ ${ }^{\mathrm{c}}$ Faculty of Engineering Technology, Univeristy of Twente, Enschede, Netherlands
}

\section{A R T I C L E I N F O}

\section{Keywords:}

Plant succession sequence

Regeneration

Plant assembly

Dispersal

Marsh restoration

Seed density

\begin{abstract}
A B S T R A C T
In salt marshes, abiotic factors, interspecific competition or facilitation, and herbivory have been discussed extensively as important drivers of marsh plant distribution patterns. However, the relative importance of various regeneration processes across stress gradients received little attention, despite their importance in explaining plant community dynamics. In this study, we built a stage-structured plant assembly model to study how the influence of each regeneration process on plant assembly dynamics varies with environmental stress level, plant succession stage and initial seed availability, in a salt marsh in Yellow River Delta National Nature Reserve in China. We found plant assembly at higher saline conditions is mainly governed by stress tolerance regardless of the stage of succession and initial seed availability, as salinity stress can suppress biomass accumulation and propagule production of salt intolerant species. Under less saline conditions with high seed availability, juvenile competition plays the most important role throughout succession. When initial seed availability is low, dispersal is more important at the beginning, but juvenile competition is more important at later stage and determines the plant competition outcomes. Our findings imply seed availability is important in determining plant succession trajectories under less stressful conditions, and should be given more attention during restoration management in coastal marshes.
\end{abstract}

\section{Introduction}

In coastal marshes, abiotic factors (Crain et al., 2004; He et al., 2009a), interspecific competition or facilitation (Bertness and Callaway, 1994; He et al., 2013; Qi et al., 2018) and herbivory (Alberti et al., 2008; Holdredge et al., 2009; He et al., 2014) have been discussed extensively as important drivers of marsh plant distribution and abundance patterns along stress gradients. Because of this, traditional restoration management of coastal marshes has focused mainly on restoring the abiotic environment (Wolters et al., 2005; Garbutt and Wolters, 2008; Cui et al., 2009). However, restored marsh habitats sometimes fail to achieve species occurrence equivalent to their reference sites, and simply replicating physical conditions does not guarantee biological equivalence (Seabloom and van der Valk, 2003; Gornish et al., 2019). Therefore, understanding community assembly rules in restored marshes is essential for successful marsh restoration.

For a dynamic plant community, its establishment depends on three critical regeneration stages: 1) seed/propagule dispersal, 2) colonist establishment or recruitment, 3) species interactions (Crain et al., 2008). Environmental context can affect each of these stages, since seed/propagule density varies with abiotic conditions (Crain et al., 2008; Janousek and Folger, 2013), seed germination and seedling establishment depend on environmental conditions (Engels et al., 2011; Liu et al., 2013), and species interactions shift along environmental gradients (Bertness and Callaway, 1994; Qi et al., 2018). |Plant traits variation during a given stage of regeneration sometimes explains plant zonation along stress gradients. For example, it was found that germination traits can explain deterministic processes in the assembly of early successional coastal dune and marsh vegetation (Liu et al., 2013; Green and Miller, 2019). During seedling establishment and/or juvenile competition stage, stress tolerance and biotic interactions were confirmed to determine plant zonation patterns in estuarine marshes (Crain et al., 2004; Engels et al., 2011). In fact, in many cases, these regeneration processes are not mutually exclusive, and they may function simultaneously to

\footnotetext{
* Corresponding author,

E-mail address: suntao@bnu.edu.cn (T. Sun).
} 
influence community structure (Crain et al., 2008). For instance, adult occupancy has direct feedbacks on the supply of new colonists (Rand, 2000; Crain et al., 2008). The challenge is to understand the relative influence of each type of regeneration process on plant assembly across different environmental conditions.

Few studies compared the relative importance of the above processes in affecting plant assembly across environmental gradients. A limited number of studies focused on processes at a broader category, i.e. deterministic (e.g. competition and environmental conditions) versus stochastic processes (processes related to dispersion, biogeography and species evolution) along environmental gradients based on statistical analysis of field surveys. For example, it was found that the composition of plant communities in salt marsh and other habitats were more influenced by deterministic than stochastic effects in severe environmental conditions compared with benign environmental conditions (Chase, 2007, 2010; Guo et al., 2014). However more recently, Michalet et al. (2015) found that in salt marsh communities, deterministic processes were more important in conditions of either high competition or high stress and that stochastic processes were important in more species-rich communities. Similar results were also found in grassland and mountain systems (Conradi et al., 2017; Wang et al., 2019). General observations in terrestrial ecosystems showed that late succession stage was deterministically structured whereas early succession was dominated by more stochastic features (Tsuyuzaki, 1989; Leps et al., 2000). In contrast, Erfanzadeh et al. (2010) found vegetation composition of the early successional stage in newly formed salt marsh appeared to be at least as much determined by the combined effect of the measured abiotic factors as that of the old marsh.

Based on bare patch colonization experiment along salinity gradients in a New England salt marsh, Crain et al. (2008) found that with the increase of salinity level, plant succession sequence shifted from tolerance model of succession (numerous species colonize from seed and are slowly displaced by clonal grasses whose recovery is slowed by preemptive competition from seedlings) to facilitated succession (stress tolerant species colonize first and facilitate stress intolerant species). They also found the importance of seed dispersal, seed bank density and seedling density was dramatically greater in oligohaline than brackish or salt marshes, likely due to larger species pool, greater seed production, and less limiting environmental conditions in less saline marshes.

The sequence of species establishment in restored coastal marshes was, in some cases, driven by their stress tolerance and competitive ability (Wolters et al., 2008), while in other cases driven by more stochastic processes, such as seed pool composition and seed densities (Seabloom and van der Valk, 2003; Garbutt and Wolters, 2008; Gornish et al., 2019). Unfortunately, in these studies, stress levels, succession stages, as well as seed pool conditions were seldom taken as variables that might drive succession into different trajectories and generate diverse plant succession sequences.

In this paper, we aimed to study how the influence of each regeneration process on plant assembly dynamics varies with environmental stress levels, plant succession stage and initial seed availability. To achieve this goal, we developed a stage-structured spatially explicit model that involved major regeneration processes, such as propagule dispersal, colonist establishment or recruitment, and species interactions. The model was calibrated and validated in a coastal marsh in Yellow River Delta (YRD). To quantify the influences of various regeneration processes, we constructed indicators corresponding to each regeneration process as inspired by 'key factor analysis', which was used to identify factors that contribute significantly to the variation in population (Varley and Gradwell, 1970). By disentangling the influence of each regeneration process and clarifying how they vary with stress levels, succession stage and seed availability, we aim to provide a multidimensional perspective in understanding plant assembly dynamics in coastal marshes, and offer guidance for organizing effective marsh management efforts.

\section{Methodology}

\subsection{Study area}

We chose Yellow River Delta Nature Reserve (Fig. 1) in Shandong Province, China for this study, as plant zonation governed by abiotic stress and interspecific interactions was observed along the environmental stress gradient (He et al., 2009a, 2011). This region is characterized by a warm, temperate, and continental monsoon climate with distinct seasons and a hot rainy summer. As a result, soil-pore-water salinity levels in the summer can vary substantially, reaching a peak of 120 PSU in high marshes, and approximately 4 PSU in uplands (Qi et al., 2018). The flora of the estuary is relatively homogeneous and plant zonation in the marshes is dominated by biological interactions and abiotic stresses across elevation gradients, such as soil salinity and tidal flooding regime (Cui et al., 2008; He et al., 2009b, 2011; Cui et al., 2010; He et al., 2011, 2012).

The main vascular plant species include Phragmites australis (dominates uplands near the river course), Tamarix chinensis (a perennial shrub that dominates terrestrial borders of the salt marshes), Suaeda salsa (dominates high and low marshes), and an invasive grass native to North America, Spartina alterniflora, which became a dominant species in the mudflats (Qi et al., 2017). Other plant species, such as Salicornia europaea, Scirpus spp., and Juncus spp occur only sparsely in small patches in the marsh habitats.

High elevation habitats, including uplands, terrestrial borders, and high marshes were used as our study area (outlined by gray dash line in Fig. 1), where the wide salinity gradient is the dominant abiotic stress and is also the only physical stress considered in a previous modeling study (Qi et al., 2018) and this one. The three dominant species we simulated were $P$. australis, T. chinensis, and S. salsa.

\subsection{Model structure}

The stage-structured model we developed has a yearly time step and a spatial resolution of $2 \mathrm{~m}$. In order to reduce the amount of computation, each pixel has one plant status (P. australis, T. Chinensis, S. suaeda, or vacant) within a regeneration cycle. Plant biomass at each pixel was also calculated at each time step. Within each time interval (or year), four main regeneration processes were simulated to generate the status

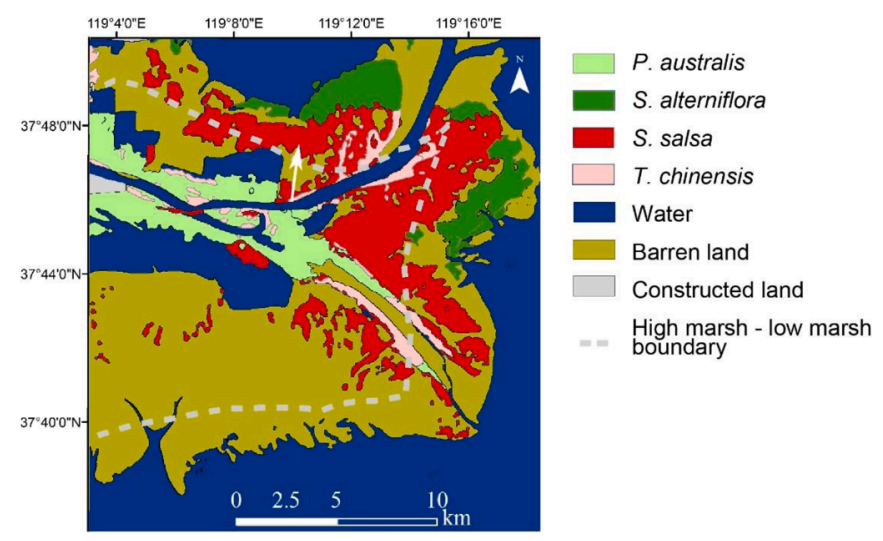

Fig. 1. Location and plant distribution of Yellow River Delta Natural Reserve. The plant distribution was produced using supervised maximum-likelihood classification from Landsat 8 remote sensing image of 2014 (Qi et al., 2017). The boundary between high marsh and low marsh was generated with digital elevation map (Qi et al., 2017) and mean high water level (from Jan. 2013 to Dec. 2016) of the nearest tidal gauge 'Doying port' (data source: http://www. chinaports.com/tidal; last accessed in May 2017). The white arrow indicates the change direction of sainity gradient (from low to high) along which a plant distribution field survey was conducted in 2015 (see details in Qi et al. (2018)). The field survey was used to calibrate the model constructed in this study. 
and plant biomass of the next year. These four regeneration processes includes propagule production, propagule dispersal, colonist establishment or recruitment, and juvenile competition and establishment (Fig. 2). Since facilitative interactions among marsh plants due to soil salinity alleviation by the occurrence of neighboring plants is also important in governing plant distributions (Qi et al., 2018), the alleviation of surface soil salinity stress by plant shading was also incorporated in the model.

\subsubsection{Propagule production}

As reviewed by Larson and Funk (2016), seed production is mainly limited by abiotic resources (sunlight, water, nutrients etc.) and biotic perturbations. Plant traits, such as height, mass, flower morphology is relevant to seed production ability. Here we choose aboveground biomass $\left(b_{i o}\right)$ as the indicator of seed production ability and assume seed production is positively related to $b_{i o_{i}}$. Therefore, the seed number produced within a pixel $\left(\right.$ seed $\left._{i}\right)$ can be expressed asseed $d_{i}^{\max }\left(\text { bio }_{i} / \text { bio }_{i}^{\max }\right)^{\theta_{1}}$, where seed $_{i}^{\max }$ and $b i o_{i}^{\max }$ represent the maximum seed number and maximum fresh weight of aboveground biomass that species $i$ can achieve respectively at optimum conditions; $b i o_{i}$ is the fresh weight of aboveground plant biomass within a pixel. $\theta_{1}$ is a coefficient that determines the relationship between vegetation aboveground biomass and seed number, and $\theta_{1}>0 . b i o_{i}^{\max }$ is calculated from our previous plant field survey in 2015, and the stress tolerance curve of simulated species (Qi et al., 2018).

In terms of species with asexual reproduction, i.e. $P$. australis, we assume the bud number produced within a pixel $\left(b u d_{i}\right)$ is related to aboveground biomass $\left(\right.$ bio $\left._{i}\right)$ since rhizome biomass is generally proportional to aboveground biomass according to our previous observations (unpublished results). The expression is $b u d_{i}^{\max }\left(b i o_{i} / b i o_{i}^{\max }\right)^{\theta_{2}}$, where $b u d_{i}^{\max }$ represents the maximum bud number at optimum condition; $\theta_{2}$ is a coefficient that determines the relationship between aboveground biomass and bud number, and $\theta_{2}>0$.

\subsubsection{Propagule dispersal}

Seed dispersal agents can be generally classified as wind, water, and animals. As high marsh and upland area is infrequently flooded and mammals are rarely observed in this areas, we took Wald analytical long-distance dispersal model (WALD) to estimate the dispersal kernels of wind-dispersal seeds (Katul et al., 2005). In WALD model, seed dispersal is driven by plant traits, which include wind speed at canopy height $(u *)$ seed terminal velocity $\left(v_{t}\right)$, canopy height $(h)$, and leaf area index $(L A I)$. Detailed structure of WALD can be found in Appendix A: Section A.

For species whose seeds are too heavy to be dispersed by wind (i.e. S. salsa), we took a simplified exponential dispersal function (Eq. (1)) to estimate seed dispersal kernels. Similarly, the local dispersal of buds was also expressed by exponential kernel

$p(x)=\frac{1}{\varphi} e^{-x / \varphi}$

where $\varphi$ is the mean dispersal distance (m).

\subsubsection{Colonist establishment or recruitment}

After seed dispersal, each pixel has a seed pool (bud pool for $P$. australis) which contains all seeds/bud dispersed from neighboring pixels. Since buds rarely stay dormant over the whole vegetation season or longer (Klimesova and Klimes, 2007), in this model we neglect seasonal dormancy of $P$. australis's buds and assume they would all sprout within a growing season. Seed germination rate $\left(g_{i}\right)$ is affected by soil salinity level, and refers to a germination experiment by Liu et al. (2013) (see detailed germination rate in Appendix A: Fig. A3). Thus for each pixel, the amount of vigorous propagules (including seedlings and vegetative runners) that transfer into clonists $\left(n_{i}\right)$ equals $n_{i}^{s d} g_{i}+n_{i}^{\text {bud }}$, where $n_{i}^{\text {sd }}$ and $n_{i}^{\text {bud }}$ are the number of seeds and buds of species $i$, respectively. As there is dramatic decrease in seed density within a regeneration cycle (Wang et al., 2009), and the viability of ungerminated seeds declines over time and also changes with the depth they were buried and other influential factors (Omami et al., 1999; Company et al., 2019), thus we assume ungerminated seeds lost viability and will not accumulate to the second year. We expect this assumption would have limited impact on our model results as all simulations start from empty seed bank pool, and the input physical conditions are stable over time in our simulation experiments.

\subsubsection{Juvenile competition and establishment}

For the competition of juveniles, we used a simplified individual based asymmetric growth model (Damgaard and Weiner, 2008) to identify the superior competitor (see details in Appendix A: section C), and the superior competitor is the one that has the highest value of $n_{i}\left(V_{i} r_{i}+r_{i}-1\right)$, where $n_{i}$ is the total number of juveniles; $V_{i}$ is the initial biomass of juveniles, and $r_{i}$ is the mean intrinsic growth rate of species $i$ at juvenile stage. We took 8-week-old seedlings as the beginning of juvenile competition, thus $v_{i}$ is the biomass of an 8-week-old

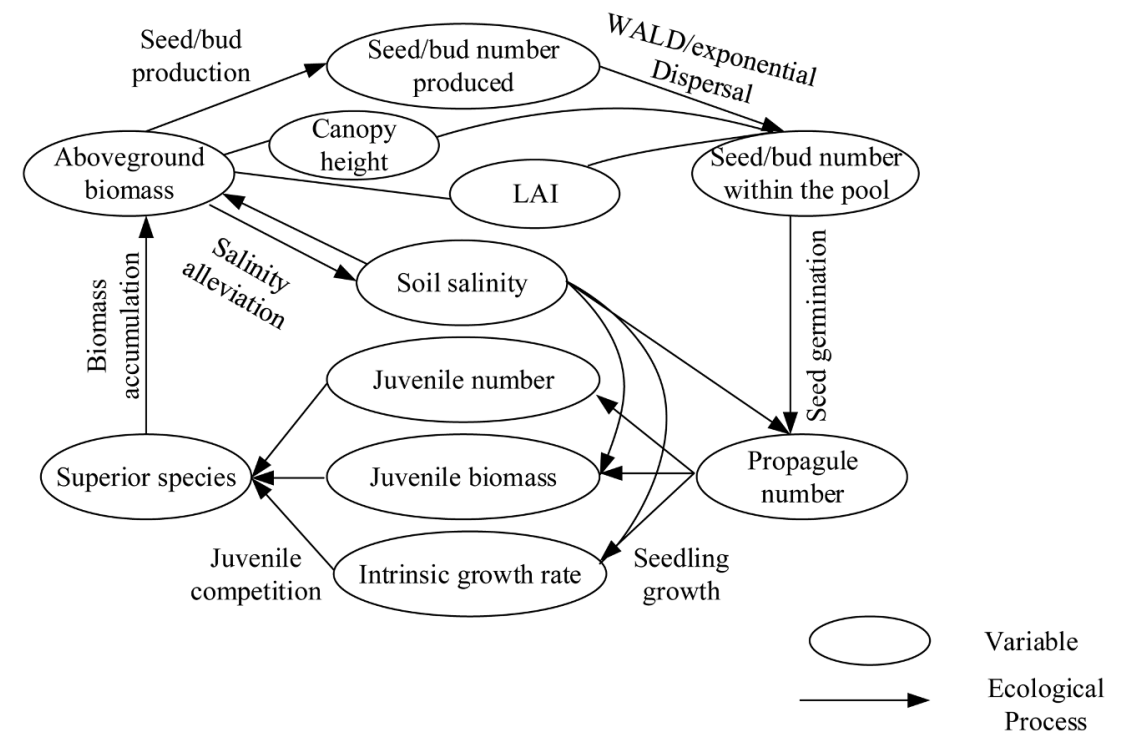

Fig. 2. Conceptual diagram of the stage-structured plant assembly model. 
seedling of species $i$, which varies with salinity level (Appendix A: Fig. A3b). As $r_{i}$ is relevant to the competitive ability of species $i$ and changes with stress levels, we assumed it is equal to Relative Stress Tolerance Curve (RSTC, Qi et al., 2018).

RSTC reflects the variation of plant's competitive ability along the stress gradient, and can be represented as $\mathrm{c}_{\mathrm{i}} \exp \left(-0.5\left(s_{t}-\mathrm{m}_{\mathrm{i}}\right)^{2} / \sigma_{\mathrm{i}}\right)$, where $c_{i}$ is a constant $\in[0,1]$ that represent the competitive ability of species $i$ at its fundamental niche optima; $s_{t}$ represents the salinity level to which the species is exposed; $m_{i}$ is the most suitable environmental conditions of species $i$; and $\sigma_{\mathrm{i}}$ is a constant reflecting the salinity tolerance range of species $i$.

Biomass of the winner species is calculated with a zero-dimensional system dynamic model by Qi et al. (2018), where biomass of the winner species at time $t$ is determined by its biomass at previous time step $t-1$, soil salinity level $\left(s_{t}\right)$ at time $t$, its competitive ability $\left(\mathrm{c}_{\mathrm{i}}\right)$, and its salinity tolerance. At each time step, if the winner species is different from that of the last time step, then we took zero as the plant biomass of previous time step. Otherwise, if the winner species is the same to the pre-existing species, the biomass of the last time step was used.

Plants considered in our model have various growth forms, for example, T. chinensis is a shrub, $S$. salsa is an annual plant, and $P$. australis is a herbaceous perennial. Therefore, the rule of displacement highly depends on the preexisting plants. Specifically, T. chinensis has a mortality rate of $1 / 6$ as the oldest $T$. chinensis individuals we observed in this area are roughly six years old. If the focal pixel is occupied by living T. chinensis, juveniles of other species will not displace it unless the biomass of $T$. chinensis is less than a given threshold (bio thh $_{\text {), below }}$ which we assumed the effect of living T. chinensis on the establishment of other juveniles is neglectable. Otherwise, if the focal pixel is preoccupied by annual plants or herbaceous perennials, it will not affect juvenile establishment of the next year because aboveground biomass of both $S$. salsa and $P$. australis would senesce every year.

\subsubsection{Salinity stress alleviation by neighboring species}

Salinity alleviation process is also included in this model as neighboring species help to alleviate salinity stress by reducing soil evapotranspiration and salinity uplifting from groundwater to surface soil. The salinity alleviation by plant shading increased with fresh weight of the aboveground biomass $\left(b_{i o_{i}}\right)$ and salinity level of substrate soil $\left(s_{t}\right)$; specific expression can be found in our previous work (Qi et al., 2018).

\subsection{Model calibration and validation}

We calibrated the model with a plant distribution field survey along the salinity gradient (arrow line in Fig. 1), where eight transects perpendicular to it were selected. $2 \times 2 \mathrm{~m}$ quadrats were placed every $100 \mathrm{~m}$ along each transect (5-8 quadrats per transect). Aboveground biomass of each species within a quadrat was recorded, and the mean aboveground biomass of each species along a given transect was calculated and used for model calibration (see detailed method in Qi et al., 2018).

To calibrate the model, we designed a $100 \times 141$-pixel habitat (each pixel is $2 \times 2 \mathrm{~m}$ hereafter). Within the habitat, soil salinity is identical at each column (100 pixels per column), and linearly increases from 0 to 140 PSU along a row (140 pixels per row). Initial plant distribution followed random distribution with a total plant cover of $20 \%$ and roughly identical relative abundance for each species. The initial biomass of each species was set as $50 \mathrm{~g} / \mathrm{m}^{2}$. Each simulation was run 20 years, though most simulations achieved equilibrium at the seventh year. Since plant distribution is less affected by initial seed density (Appendix C: Fig. C3), and our multiple pre-simulations at $20 \%$ initial plant cover also confirmed the robustness of plant distribution at equilibrium. Thus, model under each parameter setting was run once during calibration, and the average biomass of each species at a given salinity level (i.e. at each column) was calculated at equilibrium. Parameters pending calibration (Table 1 ) were adjusted until the simulated mean
Table 1.

Parameters used in the model.

\begin{tabular}{|c|c|c|c|}
\hline Parameter & Notation & Dimension & Value \\
\hline \multicolumn{4}{|l|}{ Seed production } \\
\hline \multirow{5}{*}{$\begin{array}{l}\text { Maximum seed/bud number produced } \\
\text { by species } i \text { in a pixel (hereafter } \\
\text { species } 1 \text { is } P \text {. australis, } 2 \text { is } \\
\text { T. chinensis, and } 3 \text { is } S \text {. salsa) }\end{array}$} & $\begin{array}{l}\text { seed max } \\
1\end{array}$ & - & 421,300 \\
\hline & seed $\max$ & - & 295,600 \\
\hline & 2 & & \\
\hline & $\begin{array}{l}\text { seed max } \\
3\end{array}$ & - & 250,000 \\
\hline & $\begin{array}{l}\text { bud max } \\
1\end{array}$ & - & 4000 \\
\hline \multirow{3}{*}{$\begin{array}{l}\text { Maximum aboveground biomass (fresh } \\
\text { weight) of species } i \text { at its fundamental } \\
\text { niche optima }\end{array}$} & $b_{i o}^{\max }$ & $\left(\mathrm{g} / \mathrm{m}^{2}\right)$ & 2437.24 \\
\hline & $\mathrm{bio}_{2}^{\max }$ & $\left(\mathrm{g} / \mathrm{m}^{2}\right)$ & 3137.75 \\
\hline & $\operatorname{bio}_{3}^{\max }$ & $\left(\mathrm{g} / \mathrm{m}^{2}\right)$ & 5910.15 \\
\hline $\begin{array}{l}\text { Coefficient that determines the } \\
\text { relationship between aboveground } \\
\text { biomass and seed number }{ }^{c}\end{array}$ & $\theta_{1}$ & - & 1 \\
\hline $\begin{array}{l}\text { Coefficient that determines the } \\
\text { relationship between aboveground } \\
\text { biomass and bud number }{ }^{c}\end{array}$ & $\theta_{2}$ & - & 1 \\
\hline \multicolumn{4}{|l|}{ Seed/bud dispersal } \\
\hline Wind speed at canopy height ${ }^{d}$ & $\mu_{*}$ & $\mathrm{~m} / \mathrm{s}$ & 0.55 \\
\hline $\begin{array}{l}\text { Coefficient that determines the } \\
\text { relationship between aboveground } \\
\text { biomass and leaf area index (LAI) }{ }^{c}\end{array}$ & $\theta 3$ & - & 1 \\
\hline $\begin{array}{l}\text { Mean dispersal distance of buds of } \\
\quad \text { P. australis }{ }^{c}\end{array}$ & $\varphi_{1}$ & $\mathrm{~m}$ & 2 \\
\hline $\begin{array}{l}\text { Mean dispersal distance of seeds of } \\
\text { S. salsa }{ }^{\text {c }}\end{array}$ & $\varphi_{3}$ & $\mathrm{~m}$ & 10 \\
\hline \multirow{5}{*}{$\begin{array}{l}\text { Maximum leaf area index of } P \text {. australis } \\
(L A I \max 1), T \text {. chinensis }(L A I \max 2) \text {, } \\
\text { and } S . \text { salsa }(L A I \max 3)^{\mathrm{e}}\end{array}$} & $L A I \max$ & $\left(\mathrm{m}^{2} / \mathrm{m}^{2}\right)$ & 4.36 \\
\hline & 1 & & \\
\hline & $L A I \max$ & $\left(\mathrm{m}^{2} / \mathrm{m}^{2}\right)$ & 0.72 \\
\hline & 2 & & \\
\hline & $\begin{array}{l}L A I \max \\
3\end{array}$ & $\left(\mathrm{~m}^{2} / \mathrm{m}^{2}\right)$ & 11.449 \\
\hline \multirow{3}{*}{$\begin{array}{l}\text { Coefficient that determines the } \\
\text { relationship between aboveground } \\
\text { biomass and canopy height } \mathrm{f}^{\mathrm{f}}\end{array}$} & $\theta 41$ & - & 0.1784 \\
\hline & $\theta 42$ & - & 0.1293 \\
\hline & $\theta 43$ & - & 0.0445 \\
\hline \multirow{6}{*}{$\begin{array}{l}\text { Coefficients that determines the vertical } \\
\text { wind characteristics (see Appendix A } \\
\text { for detials) }\end{array}$} & $\alpha$ & - & 0.06 \\
\hline & $C d$ & - & 0.2 \\
\hline & $k$ & - & 0.3 \\
\hline & $A_{u}$ & - & 2.0 \\
\hline & $A_{v}$ & - & 1.8 \\
\hline & $A_{w}$ & - & 1.16 \\
\hline \multirow{3}{*}{$\begin{array}{l}\text { Seed terminal velocity of } P \text {. australis } \\
\left(v_{t 2}\right) \text {, T. chinensis }\left(v_{t 2}\right) \text {, and } S \text {. salsa } \\
\left(v_{t 3}\right)^{\mathrm{a}}\end{array}$} & $v_{t 1}$ & $(\mathrm{~m} / \mathrm{s})$ & 0.17 \\
\hline & $v_{t 2}$ & $(\mathrm{~m} / \mathrm{s})$ & 0.22 \\
\hline & $v_{t 3}$ & $(\mathrm{~m} / \mathrm{s})$ & 2.86 \\
\hline \multicolumn{4}{|l|}{ Seed germination } \\
\hline \multirow[t]{3}{*}{$\begin{array}{l}\text { Seed germination rate of } P \text {. australis }\left(g_{1}\right) \text {, } \\
\quad \text { T. chinensis }\left(g_{2}\right) \text {, and } S \text {. salsa }\left(g_{3}\right)^{\mathrm{h}}\end{array}$} & $g_{1}$ & - & $\begin{array}{l}0.35 \exp \\
\left(-0.5 \mathrm{~s}_{\mathrm{t}}^{2}\right. \\
100)\end{array}$ \\
\hline & $g_{2}$ & - & $\begin{array}{l}0.91 \exp \\
\left(-0.5 \mathrm{~s}_{\mathrm{t}}^{2}\right. \\
500)\end{array}$ \\
\hline & $g_{3}$ & - & $\begin{array}{l}0.90 \exp \\
\left(-0.5 \mathrm{~s}_{\mathrm{t}}^{2}\right. \\
400)\end{array}$ \\
\hline \multicolumn{4}{|l|}{$\begin{array}{l}\text { Juvenile competition and } \\
\text { establishment }\end{array}$} \\
\hline $\begin{array}{l}\text { Biomass threshold of } T \text {. chinensis below } \\
\text { which the effect of living } T \text {. chinensis } \\
\text { on seedlings establishment is } \\
\text { neglectable }^{c}\end{array}$ & bio $_{\text {thh }}$ & $\mathrm{g} / \mathrm{m}^{2}$ & 2000 \\
\hline \multirow{3}{*}{$\begin{array}{l}\text { Competitive ability of } P \text {. australis }\left(\mathrm{c}_{1}\right) \text {, } \\
\text { T. chinensis }\left(\mathrm{c}_{2}\right) \text {, and } S \text {. salsa }\left(\mathrm{c}_{3}\right)^{\mathrm{b}}\end{array}$} & $\mathrm{c}_{1}$ & - & 1 \\
\hline & $\mathrm{c}_{2}$ & - & 0.5 \\
\hline & $c_{3}$ & - & 0.27 \\
\hline \multirow{3}{*}{$\begin{array}{l}\text { Most suitable salinity level of } P \text {. australis } \\
\qquad\left(\mathrm{m}_{1}\right), T \text {. chinensis }\left(\mathrm{m}_{2}\right) \text {, and } S \text {. salsa } \\
\left(\mathrm{m}_{3}\right)^{\mathrm{b}}\end{array}$} & $\mathrm{m}_{1}$ & PSU & 0 \\
\hline & $\mathrm{m}_{2}$ & PSU & 15.83 \\
\hline & $\mathrm{m}_{3}$ & PSU & 0 \\
\hline \multirow{3}{*}{$\begin{array}{l}\text { Parameters determining salinity } \\
\text { tolerance range of } P \text {. australis }\left(\sigma_{1}\right) \text {, } \\
\text { T. chinensis }\left(\sigma_{2}\right) \text {, and } S \text {. salsa }\left(\sigma_{3}\right)^{\mathrm{b}}\end{array}$} & $\sigma_{1}$ & - & 80.01 \\
\hline & $\sigma_{2}$ & - & 155.5 \\
\hline & $\sigma_{3}$ & - & 2923.56 \\
\hline
\end{tabular}

\footnotetext{
a Kleyer et al. (2008).

b Qi et al. (2018).
} 
c Calibrated.

${ }^{\mathrm{d}}$ Wind speed monitored from September to November in 2007 and 2008 (Appendix A: Fig. A2).

e (Chen et al., 2005; Chen et al., 2008; Kleyer et al., 2008; Li et al., 2014a, 2014b; Wang et al., 2016).

${ }^{\mathrm{f}}$ Field survey data (see Appendix A: Fig. A1).

g Massman and Weil (1999).

h Extracted from germination experiment result by Liu et al. (2013).

biomass of each species was approximate to field observed value. Root mean square error between the simulated and field observed biomass of each species were calculated to evaluate the approximation between simulated biomass and observed biomass.

To validate the model, we used soil salinity map of YRD produced by Yu et al. (2014) as input (see Appendix B: Fig. B1), other parameter settings were the same to what were used in model calibration. The simulated plant distribution from the upland to high marsh of YRD was validated with plant distribution map interpreted from Landsat 8 remote sensing image of 2014 (Fig. 1), which has an overall accuracy of 90\% (Appendix B: Fig. B2). Percent accuracy and Cohen's kappa statistics (Fleiss et al., 2003) were calculated to estimate the validity of model.

\subsection{Simulation experiments}

Along the stress gradient, we selected five salinity levels where the dominant species are P. australis only (1 PSU), P. australis \& T. chinensis (15 PSU), T. chinensis only (20 PSU), T. chinensis \& S. salsa (35 PSU), and $S$. salsa only (60 PSU). At each salinity level, we simulated plant community dynamics on a $200 \times 200$ pixel habitat within which the salinity level is homogenous. Plant succession simulation starts from four different initial total plant cover $(50 \%, 10 \%, 1 \%$ and $0.1 \%)$ with identical relative abundance of each species. Initial distribution of each species follows a random distribution, and the initial biomass was set as $50 \mathrm{~g} / \mathrm{m}^{2}$. For each level of initial plant percent cover, we generated 20 randomly distributed initial plant distribution maps as replicates.

We applied the idea of key factor analysis to recognize the key regeneration processes that drive plant community assembly. At each time step, we calculated population growth rate, and three other indicators that correspond to three main regeneration processes.

Population growth rate (PGR) equals the total number of pixels occupied by species $i$ at time $t+1$ divided by the total number of pixels occupied by species $i$ at time $t$. Dispersal Intensity (DI) equals the total number of pixels containing seeds/buds of species $i$ at time $t$ divided by the total number of pixels occupied by species $i$ at time $t$. Germination Extent (GE) equals the total number of pixels containing seedlings or runners of species $i$ at time $t$ divided by the total number of pixels containing seeds/buds of species $i$ at time $t$. Percentage colonization (PC) equals the total number of pixels occupied by species $i$ at time $t+1$ divided by the total number of pixels containing seedlings or runners of species $i$ at time $t$. For a given species, $P G R=D I \times G E \times P C$.

For a multiple species community, the rank of $P G R$ of interacting species at each time step indicates the overall competitive advantage of interacting species (higher PGR means higher competition advantage) and directly drives the abundance of species. Since $P G R=D I \times G E \times P C$, thus species' overall competitive advantages must attribute to accumulated competitive advantages of one or more regeneration processes (indicated by the rank of $D I, G E$ and $P C$ ). Specifically, if the order of species' competitive advantages of each regeneration process are the same to those of $P G R$, then the relative importance of each regeneration process is less prominent. In this case, the more important process would be the one that has similar difference in index values to those of $P G R$.
Otherwise, if there is only one or some regeneration processes have the same order of regeneration index to PGR, then this/these processes are more important than others, similarly the most important process can be detected by comparing the difference in index values as mentioned above.

\section{Results}

\subsection{Model calibration and validation}

The calibrated aboveground biomass of each species was highly consistent with our field surveyed results (Fig. 3), except that $P$. australis's biomass and $S$. salsa's biomass in our simulation at T. chinensis dominant habitat (salinity $<30$ PSU) were much lower than what were observed in the field. The overall root mean square error between the simulated species biomass and the field observed biomass is $183 \mathrm{~g} / \mathrm{m}^{2}$. Species specifically, the root mean square error is $223 \mathrm{~g} / \mathrm{m}^{2}$ for P. australis, $148 \mathrm{~g} / \mathrm{m}^{2}$ for T. chinensis and $170 \mathrm{~g} / \mathrm{m}^{2}$ for $S$. salsa.

The simulated distribution of $P$. australis was generally consistent with the remote sensing map results (Fig. 4). The distribution of T. chinensis was over-estimated by the model in S. salsa dominant areas, and barren marshes were occupied by $T$. chinensis and $S$. salsa in our simulation (see detailed accuracy matrix in Appendix B: Fig. B3). From upland to high marsh (outlined by gray dash lines in Fig. 4), there is an overall percent accuracy of $20 \%$ and a Cohen's kappa of 0.1115 (slight agreement sensu Fleiss et al., 2003). For vegetated marshes only (excluding barren marshes and water areas in Fig. 4b), the percent accuracy is $57 \%$, and the Cohen's kappa is 0.3745 (fair agreement sensu Fleiss et al., 2003).

\subsection{Key regeneration processes}

At initial plant percent cover of $50 \%$ (Fig. 5), we found dispersal intensity (DI), germination extent (GE) and percentage colonization (PC) of all three simulated species varied with salinity levels. At less saline conditions (salinity level $\leq 35$ PSU hereafter), $S$. salsa had higher dispersal intensity than the other two species at the beginning of succession before it was outcompeted by the latter, whereas the difference in dispersal intensity was not obvious at higher salinity level (60 PSU hereafter) where $S$. salsa was the dominant species. Germination extent of all three simulated species equaled to 1 across the salinity gradients, except that $P$. australis's germination extent dropped to 0.75 and 0.00 at 35 PSU and 60 PSU respectively before its extinction at the second simulation year. The percentage colonization of three plant species varied greatly along the stress gradient. $P C$ is the only index that has the same order of competitive advantage to that of PGR across salinity gradient and over time, which indicate that juvenile establishment is the most important process.

With the decrease of plant cover to $10 \%$ (Fig. 6), dispersal intensity and germination extent of all three interacting species did not differ much from the scenario with initial plant cover of $50 \%$, except that

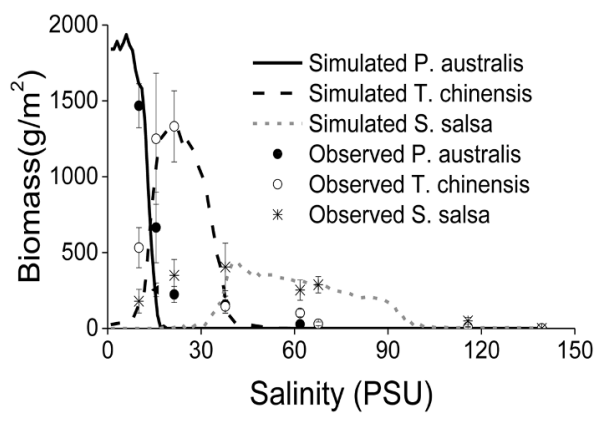

Fig. 3. . Simulated and observed distribution of each plant species across salinity gradients. 

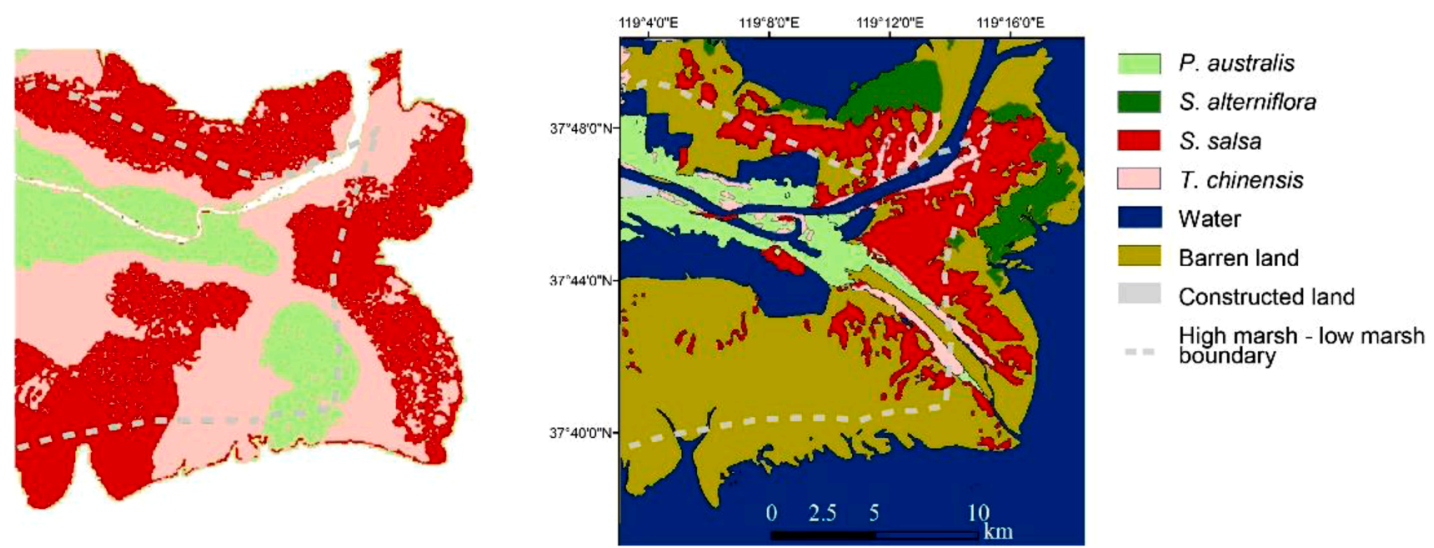

Fig. 4.. Simulated plant distribution in YRD versus plant distribution map interpreted from Landsat 8 remote sensing image acquired in 2014. The gray dash line indicates the intersection between high marsh and low marsh within which is the valid simulating area of our model since the dominant abiotic stress is soil salinity.
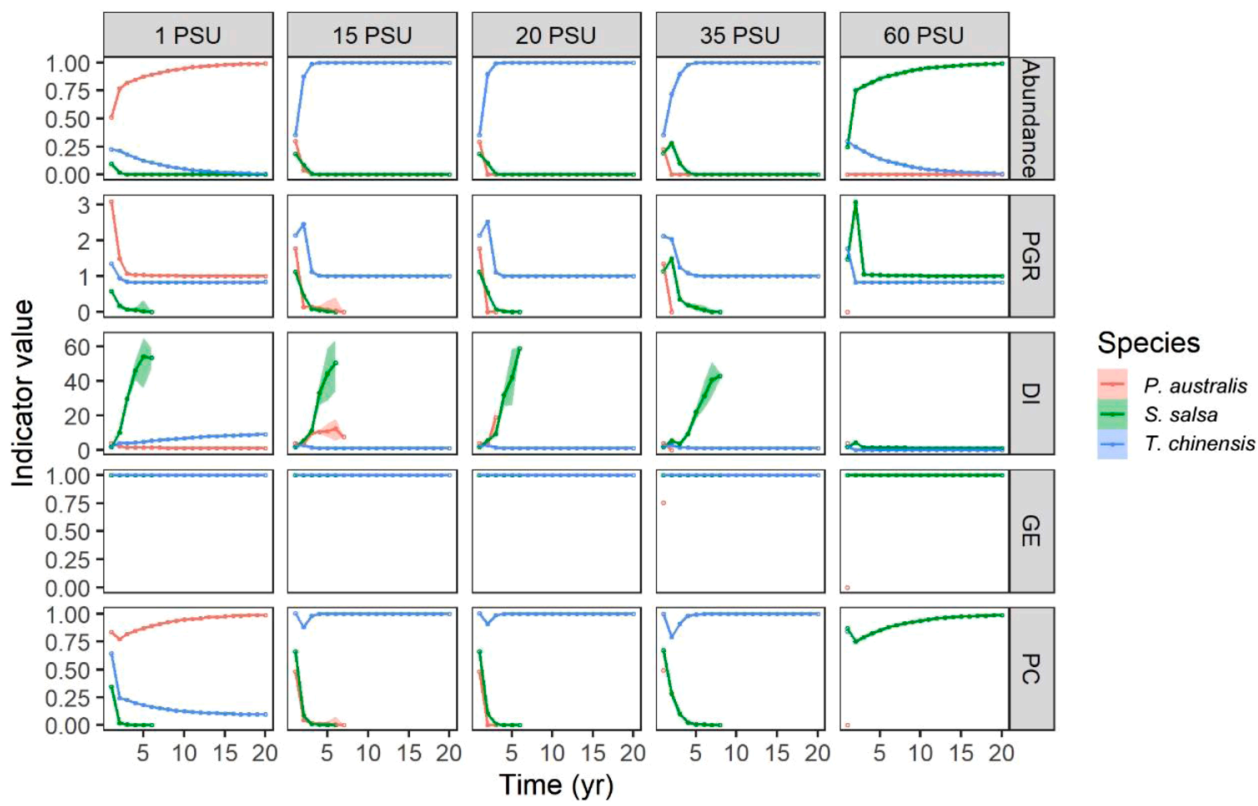

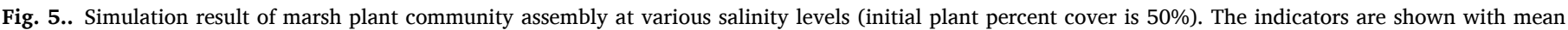

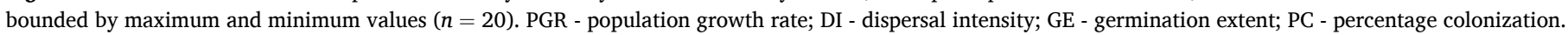

S. salsa survived longer before being outcompeted by $P$. australis and $T$. chinensis under less saline conditions. Moreover, there was an increase in the percentage colonization of $S$. salsa, and a decrease in percentage colonization of other dominant species (i.e. P. australis at 1 PSU, and T. chinensis at 15 35 PSU). As a result, there was a rapid increase in $S$. salsa's population growth rate and abundance, though it was later outcompeted by $P$. australis or $T$. chinensis at less saline conditions. Different from the scenario with initial plant cover of $50 \%$, the order of overall competitive advantage (indicated by PGR) is consistent with the competitive advantage during dispersal (indicated by DI) within the first four simulation years, followed by higher consistency between PGR and PC. Thereby across the salinity gradient, dispersal is more important during early succession and juvenile establishment is more important at late succession stage.

With the continuing decrease of initial plant cover to 1\% (Fig. 7) and $0.1 \%$ (Appendix B: Fig. B4), there was a boost in the dispersal intensity of $S$. salsa at the beginning of plant succession. Relative to the larger initial percent coverage, the percent colonization of $S$. salsa was higher accompanied by lower percent colonization of the other two species at less saline conditions. Moreover, percent colonization of S.salsa even surpassed the other two species at some point under less saline conditions. Population growth rates of interacting species initially varied closely with dispersal intensity, but later varied with percent colonization. Thereby, we observed rapid establishment of $S$. salsa (i.e. high abundance) at the beginning, but latter on $S$. salsa was displaced by $P$. australis (1 PSU) and T. chinensis (15 35 PSU). Compared with the scenario with initial plant cover of $10 \%$, the consistency between PGR and DI increased, which indicate an increasing importance of dispersal.

Plant assembly at a higher saline condition is less complicated, as $P$. australis and T. chinensis could not survive after the second simulation year, thus $S$. salsa was the only species that existed regardless of the initial plant cover. To analyze which regeneration process induces the extinction of $P$. australis and T. chinensis, we examined the regeneration processes one by one before their extinction. In terms of the extinction of $P$. australis at 35 PSU, we found that at the first year its dispersal intensity did not drop much from less stressful salinity level, whereas the germination extent was partially suppressed by salinity stress and decreased to 0.75 . Percent colonization also dropped at different extent given different initial seed availability. At the second year, the dispersal intensity of $P$. australis dropped to zero, probably because of low seed 

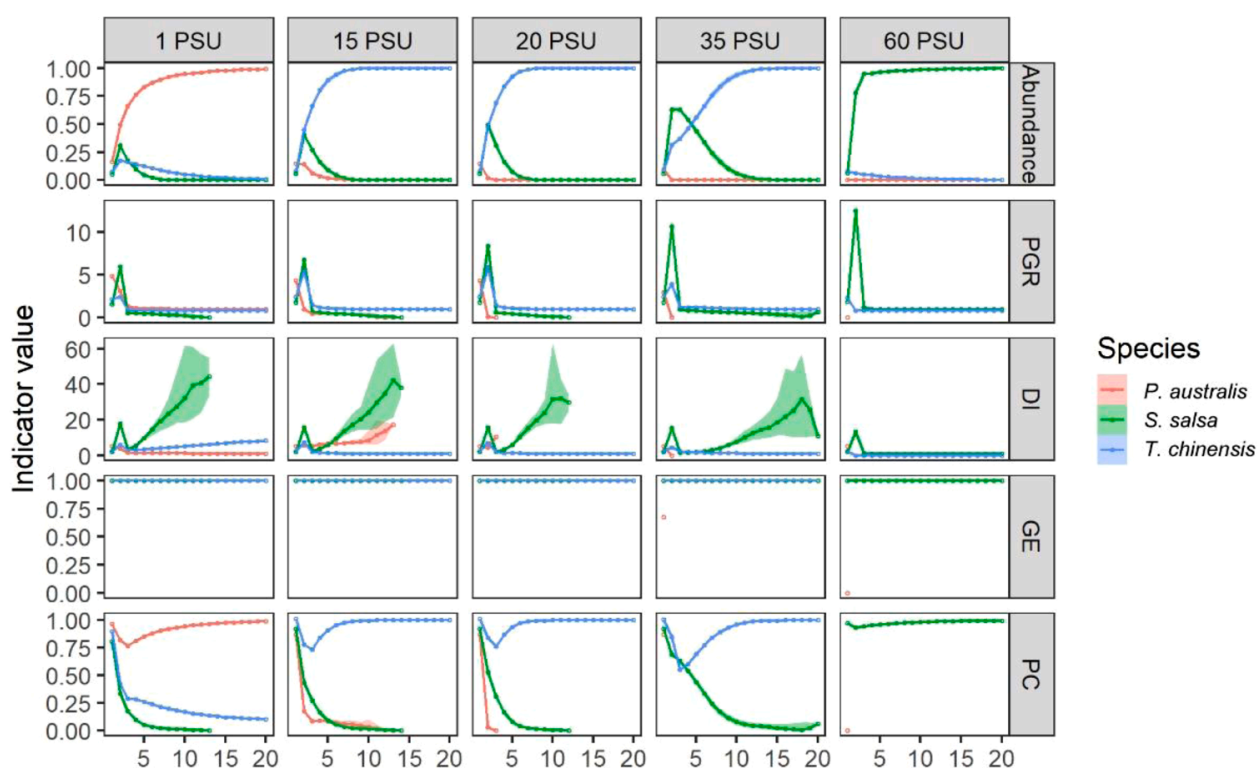

T. chinensis
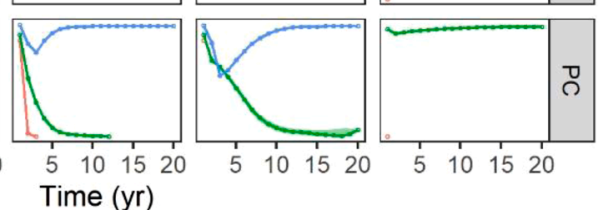

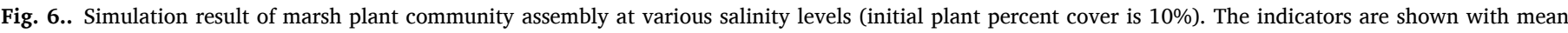

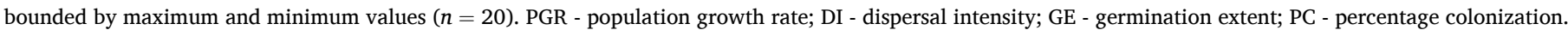
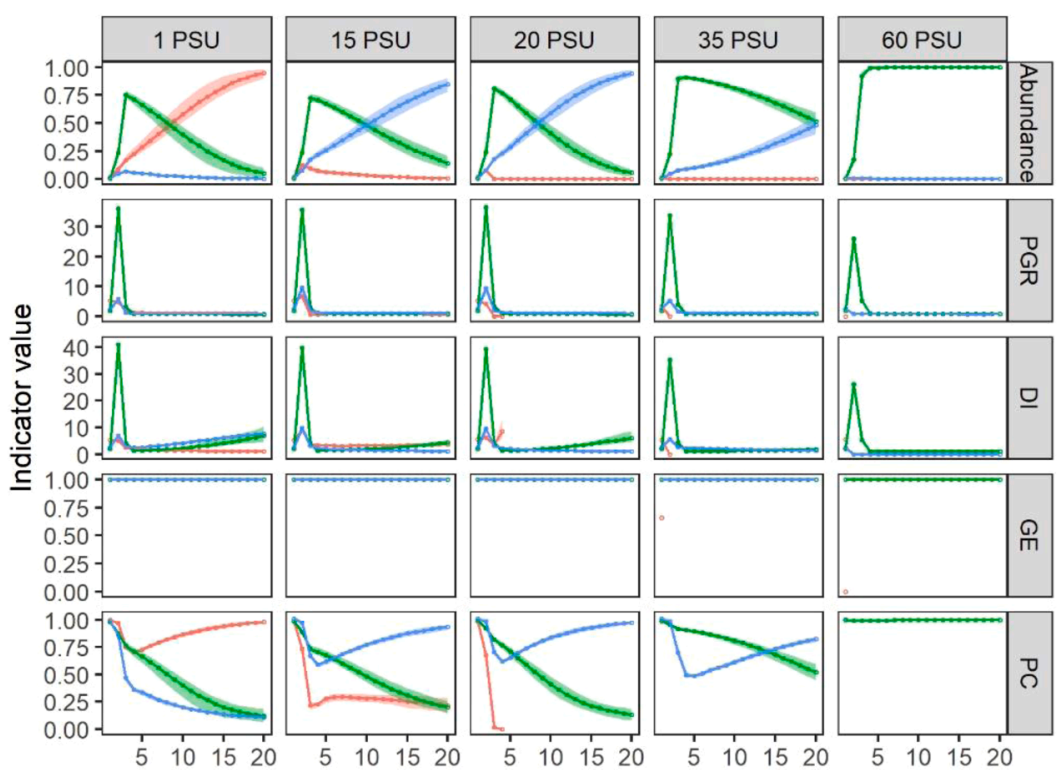

\section{Species}

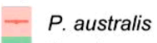

S. salsa

T. chinensis
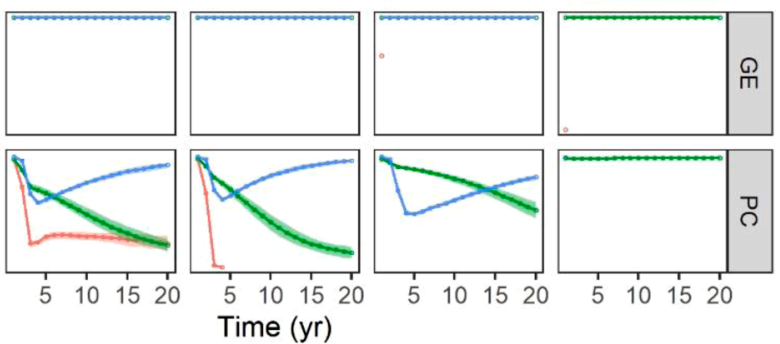

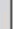

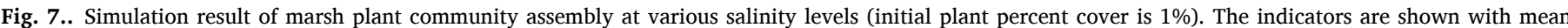

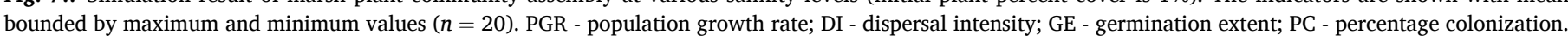

production as an outcome of insufficient biomass accumulation from the first year. Therefore, the extinction of $P$. australis at 35 PSU attributed to accumulated effects of decreased germination extent, seedling colonization and biomass accumulation. At $60 \mathrm{PSU}$, the germination extent of $P$. australis decreased to zero, which directly induced its extinction. In terms of the extinction of T. chinensis at 60 PSU, we found its dispersal intensity and seedling colonization were suppressed at the first year, whereas the germination extent was not. Importantly, its dispersal intensity of the second year dropped to zero, which implied that accumulated suppression of dispersal intensity, seedling colonization and biomass accumulation contributed to its extinction under higher saline condition.

In terms of the effect of random initial plant distribution, we found dispersal intensities of some species ( $S$. salsa in Fig. $5 \sim 6$ and $P$. australis in Fig. 7) presented high variances before their extinction. Besides, the variance of percentage colonization and abundance increased with the decrease of initial plant cover (Fig. 7 and Appendix B: Fig. B4).

\section{Discussion}

We characterized the influence of dispersal capability (indicated as DI in model result), germination extent (indicated as GE) and juvenile establishment capability (indicated as PC) on plant community assembly along soil salinity gradients with a stage-structured plant assembly model. We found that plant assembly at saline conditions is mainly governed by stress tolerance, as abiotic stress can suppress multiple 
regeneration processes of stress intolerant species before their extinction, especially biomass accumulation and seed production. Plant community assembly at less saline conditions is driven mainly by dispersal (indicated as DI) and juvenile establishment. The relative importance of dispersal and juvenile establishment varies with initial seed availability and the stage of succession. Specifically, with the decrease of initial seed availability, dispersal plays an increasingly important role in plant assembly at the beginning of succession. Over time, juvenile establishment plays an increasingly important role, and determines the final competition outcomes regardless of initial seed availability.

\subsection{Performance of the proposed plant assembly model}

The model we calibrated does not perform well in ecotone areas, possibly because 1) the structure of our model only allows one species to colonize a pixel at each time interval, thus the model only keeps the most competitive species and cuts off other subdominant species even if they might coexist with the former; 2) Our model does not consider the effect of stochastic disturbances, which might cause spatial heterogeneity, and is important in species-rich ecotones (Michalet et al., 2015; Conradi et al., 2017; Wang et al., 2019).

In model validation, the inconsistencies between the simulated plant distribution and data from the remote sensing imagery (Fig. 4) might result from several aspects. The first is the inaccuracy of input environmental conditions. For example, input soil salinity on the south bank of Yellow River may be less representative as there are fewer survey points compared with the north bank when generating the map (Appendix B: Fig. B1a). There are also several marsh restoration projects on both sides of Yellow River, where soil salinity is manually manipulated but not accurately reflected in the soil salinity map used in model calibration (Appendix B: Fig. B2a). Secondly, in high marshes where the simulated area of $S$. salsa is larger than what was derived from remote sensing images (such as at the southwest corner of the study area), the biomass of $S$. salsa is actually extremely low (Appendix B: Fig. B5), thus $S$. salsa at such low biomass (or density) was classified as barren soils (the background color) during interpretation (Appendix B: Fig. B2). Thirdly, within vegetated marsh of the simulated area, our model overestimated the distribution area of $T$. chinensis in habitats where S. salsa actually colonized (Appendix B: Fig. B3). This might attribute to the lack performance of model in ecotone areas as discussed above. Therefore, it is better to limit the prediction ability of our model to vegetated marsh where there is fair agreement between simulation and real system.

\subsection{Variation of plant community assembly dynamics along salinity gradients}

Our simulation results indicate that assembly at higher saline condition is governed by stress tolerance of interacting species and does not vary with seed availability. With the decrease of salinity level, plant assembly is influenced more by initial seed availability (Fig. 5 7). At high seed availability (initial plant cover equals $50 \%$ in our model), the most competitive species during juvenile establishment rapidly colonizes vacant space, and becomes the dominant species. Whereas at low seed availability (initial plant percent cover $\leq 10 \%$ in our model), fast dispersal species can preempt the vacant space first and become the dominant species quickly, but its dominance does not last long because the slow dispersal species with higher competitive ability can gradually displace it and become the final dominant species. The shift of plant assembly dynamics along salinity gradient we observed in the simulation is consistent with Crain et al. (2008)'s field study in a New England salt marsh, which is currently still the most systematic study of colonist recruitment along salinity gradients in coastal marshes. They found that with the decrease of salinity level, plant succession sequence shifted from facilitation succession to tolerance model of succession. The only difference is that Crain et al. (2008) did not control the seed bank density but took the natural background seed pool to conduct the experiment, thus they did not study how the succession dynamics in oligohaline (or brackish) marsh responded to different levels of seed bank densities.

Where our results seem to contradict Crain et al. (2008) is that they found plant succession sequence in oligohaline marsh (where seed bank density is high) to follow tolerance model of succession, while our results indicate that tolerance model of succession only occurs at low seed availability (initial plant percent cover is less than 50\%). This might be because what we meant by 'seed availability' here is different from 'seed bank density' used in Crain et al. (2008). In Crain's et al. (2008) study, though there is a high seed bank density in oligohaline marsh, the proportion of vegetative runners (inferior in dispersal but superior in competition) at the beginning of succession is obviously lower than seeds, thus initial density of vegetative runners is actually insufficient. Whereas in our model, we set roughly equal initial abundance of all interacting species, thus the propagule availability of interacting plant species is less disproportional. Actually, at soil salinity level of 1 PSU and initial plant percent cover of 50\%, propagule abundance (proportion of pixels containing propagules) of $P$. australis, T. chinensis, and $S$. salsa at the first time step is $61.14 \%, 35.16 \%$, and $28.09 \%$ respectively. Besides, $76.85 \%$ pixels contain propagules of $P$. australis or T. chinensis at the first time step. Therefore, by saying high seed availability, we actually mean high availability of propagules of species with high competitive abilities.

\subsection{Competition-colonization-stress tolerance trade-offs}

The simulated species presented distinct strategies in species establishment, which indicates trade-offs in compeititon-clonization-stress tolerance. Following Grimes's C-S-R theory (Grime, 1974; Hodgson et al., 1999), P. australis is competitor (C), T. chinesis is competitor \& stress tolerator (CS) and S. salsa is stress tolerator \& ruderal (SR). Along stress gradient, tradeoff between competition and stress tolerance governs the spatial distribution of marsh plant at equilibrium, which has long been demonstrated in empirical studies (Crain et al., 2004; Qi et al., 2018). Our result also confirmed that competition-colonization tradeoff affect plant succession sequence over time (Tsuyuzaki, 1989; Leps et al., 2000), and we further demonstrated that competition-colonization tradeoff promotes temporal species coexistence at less saline conditions with low seed availability, though stabilized coexistence can also be achieved under certain parameter space as proved in other simulations (Hastings, 1980; Tilman, 1994; Calcagno et al., 2006).

To clarify plant succession sequences under less stressful conditions, we can categorize species into four groups based on their competitive abilities and dispersal abilities. We found at low seed availability, dispersal plays a more important role in plant assembly, thus species with high dispersal abilities establish first. Overtime, species with high competitive abilities but low dispersal abilities gradually displace species with low competitive abilities but high dispersal abilities. At high seed availability, competitive ability plays a more important role, thus species with higher competitive abilities establish faster and become the ultimate dominant species. We suggest future marsh restoration projects to divide species in seed pool into different categories based on their competitive abilities and dispersal abilities to better foresee plant succession sequences or manipulate restoration efforts.

\subsection{Variation of the influences of regeneration processes on plant community assembly}

We found the importance of dispersal and juvenile establishment (juvenile competition to be specific, thus we use juvenile competition hereafter) are dramatically greater at less saline conditions, while juvenile biomass accumulation and seed production are more important for the survival of less salt tolerant species at higher saline conditions.

Over time, we found that the relative importance of dispersal and juvenile competition at lower saline conditions depend on initial seed 
availability (Fig. 8). At high seed availability, juvenile competition plays the most important role throughout succession, while at low seed availability, dispersal is more important at the beginning and juvenile competition is more important at the latter stage of succession. The importance of dispersal at limiting seed availability was also observed in less saline coastal marshes and restored prairie wetlands (Crain et al., 2008; Kettenring and Galatowitsch, 2011). Given some conflicting observations between salt marsh and other ecosystems (Erfanzadeh et al., 2010), we suggest future studies about plant assembly to survey seed density, and seed proportion of the abovementioned four plant groups, to make valid comparisons. In addition, as we know in salt marshes, seed availability and seed density are generally higher in benign than in severe environmental conditions, so the variation of stress level is accompanied by changes in seed availability/density. As seed availability is crucially important for plant assembly, we highly recommend that future studies clarify seed availability and physical conditions, and explore their independent effects on plant assembly instead of combined effects.

We find that a random distribution of initial plant pattern only causes high variance of species abundance and percent colonization but has limited effect on succession tendency of plant community composition. In fact, the randomness we simulate in this study is just one of many stochastic processes, e.g. stochastic disturbances on seed density or seed proportion of a given species, stochastic die-off of a patch etc. (Chase, 2007, 2010; Guo et al., 2014; Michalet et al., 2015; Conradi et al., 2017; Wang et al., 2019). To thoroughly demonstrate how the effects of these stochastic events vary along stress gradient, more simulation experiments need to be conducted, which is beyond the scope of this study.

In addition, though we incorporated shelter effect in the model, since each pixel is only occupied by one species, thus our model can not simulate interspecific facilitation during growing season, which is out of the scope of this study. However, intergenerational facilitation can exist in the model if germination rate and juvenile competition ability of late arrival species were raised because of the salinity alleviation from preexisting species. But we expect the effect of facilitation on model results is limited (see our quantitative estimation of facilitation strength in Qi et al., 2018).

\subsection{Limitations and open questions}

Our model did not consider the effect of tidal currents and microtopography on secondary seed dispersal (i.e. the movement of seeds after they have fallen to the ground (Shi et al., 2020)) and seed retention heterogeneity (Chang et al., 2008; Wang et al., 2020), which could add more stochasticity and spatial heterogeneity in seed dispersal and retention. Neither did we consider other abiotic factor (e.g. soil moisture) that might also affect seed germination or other regeneration processes (Wang et al., 2020). Thus more field experiments are encouraged to test the predictions in this model.

\section{Conclusions}

In this study, we explored the importance of regeneration processes under different conditions (stress, seed availability, succession stage) with a process-based model calibrated and validated with field data. We found extreme stress can suppress biomass accumulation and propagule production of stress intolerant species, and governs plant assembly. Under less stressful conditions, juvenile competition determines the final competition outcomes, and can be the dominant process throughout succession at high seed availability. While with the decrease of initial seed availability, dispersal plays increasingly important role at early succession stage, though juvenile competition is still the dominant process at later stage. Our study recognized the importance of seed availability in adjusting the plant assembly processes, which should be given more attention in further studies and marsh restoration projects.

\section{Declaration of Competing Interest}

The authors declare that they have no known competing financial interests or personal relationships that could have appeared to influence the work reported in this paper.

\section{Acknowledgement}

This material is financially supported by self-determined research funds of CCNU from the colleges' basic research and operation of MOE (CCNU20XJ012), Joint Funds of the National Natural Science Foundation of China (grant \# U1806217), and National Natural Science Foundation of China (grant \# 41901382).

\section{Supplementary materials}

Supplementary material associated with this article can be found, in the online version, at doi:10.1016/j.ecolmodel.2021.109646.

\section{References}

Alberti, J., Escapa, M., Iribarne, O., Silliman, B.R., Bertness, M., 2008. Crab herbivory regulates plant facilitative and competitive processes in Argentinean marshes. Ecology 89, 155-164.

Bertness, M.D., Callaway, R., 1994. Positive interactions in communities. Trends Ecol. Evol. (Amst.) 9, 191-193.

Calcagno, V., Mouquet, N., Jarne, P., David, P., 2006. Coexistence in a metacommunity: the competition-colonization trade-off is not dead. Ecol. Lett. 9, 897-907.

Chang, E.R., Veeneklaas, R.M., Buitenwerf, R., Bakker, J.P., Bouma, T.J., 2008. To move or not to move: determinants of seed retention in a tidal marsh. Funct Ecol 22, $720-727$.

Chase, J.M., 2007. Drought mediates the importance of stochastic community assembly. Proc. Natl. Acad. Sci. 104, 17430.

Chase, J.M., 2010. Stochastic community assembly causes higher biodiversity in more productive environments. Science 328, 1388.

Chen, J., Ni, S., Li, Y., 2008. LAI retrieval of reed canopy using the neural network method. Remote Sensing Land Resour. 2, 62-66.

Chen, J., Ni, S., Li, Y., Li, J., 2005. Remote sensing LAI retrieval of reed marsh. Remote Sensing Land Resour. 17, 20-23.

Company, T., Soriano, P., Estrelles, E., Mayoral, O., 2019. Seed bank longevity and germination ecology of invasive and native grass species from Mediterranean wetlands. Folia Geobot. 54, 151-161.

Conradi, T., Temperton, V.M., Kollmann, J., 2017. Resource availability determines the importance of niche-based versus stochastic community assembly in grasslands. Oikos 126, 1134-1141.

Crain, C.M., Albertson, L.K., Bertness, M.D., 2008. Secondary succession dynamics in estuarine marshes across landscape-scale salinity gradients. Ecology 89, 2889-2899.

Crain, C.M., Silliman, B.R., Bertness, S.L., Bertness, M.D., 2004. Physical and biotic drivers of plant distribution across estuarine salinity gradients. Ecology 85, 2539-2549.

Cui, B.S., He, Q., Zhao, X.S., 2008. Researches on the ecological thresholds of Suaeda salsa to the environmental gradients of water table depth and soil salinity (in Chinese). Acta Ecologica Sinica 28, 1408-1418.

Cui, B.S., He, Q.A., An, Y.A., 2011. Community structure and abiotic determinants of salt marsh plant zonation vary across topographic gradients. Estuaries Coasts 34, 459-469.

Cui, B.S., Yang, Q.C., Yang, Z.F., Zhang, K.J., 2009. Evaluating the ecological performance of wetland restoration in the Yellow River Delta, China. Ecol. Eng. 35, 1090-1103.

Cui, B.S., Yang, Q.C., Zhang, K.J., Zhao, X.S., You, Z.Y., 2010. Responses of saltcedar (Tamarix chinensis) to water table depth and soil salinity in the Yellow River Delta, China. Plant Ecol. 209, 279-290.

Damgaard, C., Weiner, J., 2008. Modeling the growth of individuals in crowded plant populations. J. Plant Ecol. 1, 111-116.

Engels, J.G., Rink, F., Jensen, K., 2011. Stress tolerance and biotic interactions determine plant zonation patterns in estuarine marshes during seedling emergence and early establishment. J. Ecol. 99, 277-287.

Erfanzadeh, R., Petillon, J., Maelfait, J.-.P., Hoffmann, M., 2010. Environmental determinism versus biotic stochasticity in the appearance of plant species in saltmarsh succession. Plant Ecol Evol 143, 43-50.

Fleiss, J.L., Levin, B., Paik, M.C., 2003. The measurement of interrater agreement. In: Shewart, W.A., Wilks, S.S., Fleiss, J.L., Levin, B., Paik, M.C. (Eds.), Statistical Methods for Rates and Proportions, pp. 598-623. https://doi.org/10.1002/ 0471445428.ch18.

Garbutt, A., Wolters, M., 2008. The natural regeneration of salt marsh on formerly reclaimed land. Appl. Vegetation Sci. 11, 335-344.

Gornish, E.S., Shaw, J., Gillespie, B.M., 2019. Using strip seeding to test how restoration design affects randomness of community assembly. Restoration Ecol. 27, 1199-1205. 
Green, M.D., Miller, T.E., 2019. Germination traits explain deterministic processes in the assembly of early successional coastal dune vegetation. Estuaries Coasts 42 , 1097-1103.

Grime, J.P., 1974. Vegetation classification by reference to strategies. Nature 250, 26-31.

Guo, H., Więski, K., Lan, Z., Pennings, S.C., 2014. Relative influence of deterministic processes on structuring marsh plant communities varies across an abiotic gradient. Oikos 123, 173-178.

Hastings, A., 1980. Disturbance, coexistence, history, and competition for space. Theor Popul Biol 18, 363-373.

Hodgson, J.D., Wilson, P.J., Hunt, R., Grime, J.P., Thompson, K., 1999. Allocating CSR plant functional types: a soft approach to a hard problem. Oikos 85, 282-294.

He, Q., Altieri, A.H., Cui, B., 2014. Herbivory drives zonation of stress tolerant marsh plants. Ecology.

He, Q., Bertness, M.D., Altieri, A.H., 2013. Global shifts towards positive species interactions with increasing environmental stress. Ecol. Lett. 16, 695-706.

He, Q., Cui, B., An, Y., 2011. The importance of facilitation in the zonation of shrubs along a coastal salinity gradient. J. Vegetation Sci. 22, 828-836.

He, Q., Cui, B., Zhao, X., Fu, H., Liao, X., 2009a. Relationships between salt marsh vegetation distribution/diversity and soil chemical factors in the Yellow River Estuary, China. Acta ecologica sinica/Shengtai Xuebao 29, 676-687.

He, Q., Cui, B.S., Bertness, M.D., An, Y., 2012. Testing the importance of plant strategies on facilitation using congeners in a coastal community. Ecology 93, 2023-2029.

He, Q., Cui, B.S., Cai, Y.Z., Deng, J.F., Sun, T., Yang, Z.F., 2009b. What confines an annual plant to two separate zones along coastal topographic gradients? Hydrobiologia 630, 327-340.

Holdredge, C., Bertness, M.D., Altieri, A.H., 2009. Role of crab herbivory in die-off of New England Salt Marshes. Conservation Biol. 23, 672-679.

Janousek, C.N., Folger, C.L., 2013. Inter-specific variation in salinity effects on germination in Pacific Northwest tidal wetland plants. Aquat. Bot. 111, 104-111.

Katul, G.G., Porporato, A., Nathan, R., Siqueira, M., Soons, M.B., Poggi, D., et al., 2005. Mechanistic analytical models for long-distance seed dispersal by wind. Am Nat 166, 368-381.

Kettenring, K.M., Galatowitsch, S.M., 2011. Seed rain of restored and natural Prairie Wetlands. Wetlands 31, 283-294.

Kleyer, M., Bekker, R.M., Knevel, I.C., Bakker, J.P., Thompson, K., Sonnenschein, M., et al., 2008. The LEDA Traitbase: a database of life-history traits of the Northwest European flora. J. Ecol. 96, 1266-1274.

Klimesova, J., Klimes, L., 2007. Bud banks and their role in vegetative regeneration - A literature review and proposal for simple classification and assessment. Perspect Plant Ecol. Evol. Systematics 8, 115-129.

Larson, J.E., Funk, J.L., 2016. Regeneration: an overlooked aspect of trait-based plant community assembly models. J. Ecol. n/a-n/a.

Leps, J., Michálek, J., Rauch, O., Uhlík, P, 2000. Early succession on plots with the upper soil horizon removed. J. Vegetation Sci. 11, 259-264.

Li, Y., Kang, X., Hao, Y., Ding, K., Wang, Y., Cui, X., et al., 2014a. Carbon, water and heat fluxes of a reed (Phragmites australis) wetland in the Yellow River Delta, China. Acta Ecologica Sinica 34, 4400-4411.

Li, Y., Mao, D., Wang, Z., Lu, C., Zhang, L., Lou, Y., 2014b. Remote sensing retrieval and spatial pattern analysis of leaf area index of Phragmites australis in Shuangtai Estuary National Nature Reserve. Wetland Sci. 12, 163-169.
Liu, X., Wang, C., Su, Q., 2013. Screening for salt tolerance in eight halophyte species from yellow river delta at the two initial growth stages. ISRN Agronomy, 20138.

Massman, W., Weil, J., 1999. An analytical one-dimensional second-order closure model of turbulence statistics and the Lagrangian time scale within and above plant canopies of arbitrary structure. Boundary Layer Meteorol 91, 81-107.

Michalet, R., Maalouf, J.-.P., Choler, P., Clément, B., Rosebery, D., Royer, J.-.M., et al., 2015. Competition, facilitation and environmental severity shape the relationship between local and regional species richness in plant communities. Ecography 38, 335-345.

Omami, E.N., Haigh, A.M., Medd, R.W., Nicol, H.I., 1999. Changes in germinability, dormancy and viability of Amaranthus retroflexus as affected by depth and duration of burial. Weed Res. 39, 345-354.

Qi, M., Sun, T., Xue, S., Yang, W., Shao, D., Martínez-López, J., 2018. Competitive ability, stress tolerance and plant interactions along stress gradients. Ecology 99, 848-857.

Qi, M., Sun, T., Zhang, H., Zhu, M., Yang, W., Shao, D., et al., 2017. Maintenance of salt barrens inhibited landward invasion of Spartina species in salt marshes. Ecosphere 8, e01982.

Rand, T.A., 2000. Seed dispersal, habitat suitability and the distribution of halophytes across a salt marsh tidal gradient. J. Ecol. 88, 608-621.

Seabloom, E.W., van der Valk, A.G., 2003. The development of vegetative zonation patterns in restored prairie pothole wetlands. J. Appl. Ecol. 40, 92-100.

Shi, W., Shao, D., Gualtieri, C., Purnama, A., Cui, B., 2020. Modelling long-distance floating seed dispersal in salt marsh tidal channels. Ecohydrology 13.

Tilman, D., 1994. Competition and biodiversity in spatially structured habitats. Ecology 75, 2-16.

Tsuyuzaki, S., 1989. Contribution of buried seeds to revegetation after eruptions of the volcano Usu, Northern Japan. The botanical magazine = Shokubutsu-gaku-zasshi 102, 511-520.

Varley, G.C., Gradwell, G.R., 1970. Recent advances in insect population dynamics. Annu. Rev. Entomol. 15, 1-24.

Wang, C.-h., Tang, L., Fei, S.-f., Wang, J.-q., Gao, Y., Wang, Q., Chen, J.-k., Li, B., 2009. Determinants of seed bank dynamics of two dominant helophytes in a tidal salt marsh. Ecol Eng 35, 800-809.

Wang, D., Bai, J., Wang, W., Ma, X., Guan, Y., Gu, C., et al., 2020. Micro-topography manipulations facilitatesuaeda salsamarsh restoration along the lateral gradient of a tidal creek. Wetlands 40, 1657-1666.

Wang, J., Ding, L., Cheng, Q., 2016. Research on the effect of wetland vegetation LAI on the Relationship between LUE and PRI by in situ data and PROSPECT-SAIL Model. J. Nat. Resources 31, 514-525.

Wang, Y., Li, C., Shen, Z., Rui, J., Jin, D., Li, J., et al., 2019. Community assemblage of free-living diazotrophs along the elevational gradient of Mount Gongga. Soil Ecol. Lett. 1, 136-146.

Wolters, M., Garbutt, A., Bakker, J.P., 2005. Plant colonization after managed realignment: the relative importance of diaspore dispersal. J. Appl. Ecol. 42, 770-777.

Wolters, M., Garbutt, A., Bekker, R.M., Bakker, J.P., Carey, P.D., 2008. Restoration of salt-marsh vegetation in relation to site suitability, species pool and dispersal traits. J. Appl. Ecol. 45, 904-912.

Yu, J.B., Li, Y.Z., Han, G.X., Zhou, D., Fu, Y.Q., Guan, B., et al., 2014. The spatial distribution characteristics of soil salinity in coastal zone of the Yellow River Delta. Environ Earth Sci 72, 589-599. 